\title{
Quantile regression models for fish recruitment-environment relationships: four case studies
}

\author{
Benjamin Planque ${ }^{1,2, *}$, Laure Buffaz ${ }^{1}$ \\ ${ }^{1}$ Département Ecologie et Modèles pour l'Halieutique, Ifremer, rue de l'île d'Yeu, 44311 Nantes Cedex 3, France \\ ${ }^{2}$ Present address: Institute of Marine Research, Postboks 6404, 9294 Tromsø, Norway
}

\begin{abstract}
Understanding and modelling the environmental control of fish recruitment has been a central question in fish population ecology for the last century. Most environment-recruitment models have primarily been developed to model mean recruitment using conventional regression techniques which assume that all environmental parameters are included and that the residual unexplained variability is unstructured. However, the complexity of environmental controls and the empirical evidence that many relationships have failed when retested suggest that these assumptions are generally not met. Most environmental controls may be considered as limiting factors to recruitment and act in interaction with other factors (often not measured or not known). We used quantile regression modelling, which is specifically designed to model limiting relationships, to reanalyse environment-recruitment relationships that have been published for 4 fish stocks: (1) Northeast Arctic cod (Barents Sea), (2) Atlanto-Scandian herring, (3) Bay of Biscay anchovy and (4) Pacific sardine. The method was adapted to the specific case of autocorrelated time series, a common feature of most environmental signals. The results from quantile regression were not straightforward extensions of conventional regressions. For Northeast Arctic cod and Pacific sardine, the original relationships with temperature were not statistically significant in the quantile model. For Atlanto-Scandian herring the relationship was confirmed and temperature clearly appeared as a limiting factor to recruitment. The published relationship for the Bay of Biscay anchovy with upwelling was not confirmed, but the previously undetected relationship with river runoff was established. In this specific case, it was only by using a quantile model that the relationship could be detected as statistically significant. These results confirm the ability of quantile regression models to provide robust interpretation of environment-recruitment relationships and to produce environmentally based advance warning when recruitment is expected to be low.
\end{abstract}

KEY WORDS: Environment-recruitment - Quantile regression models • Northeast Arctic cod • Atlanto-Scandian herring · Bay of Biscay anchovy - Pacific sardine · Autocorrelated time series

\section{INTRODUCTION}

Understanding the fluctuations in population abundance is a central question in ecology. For exploited marine populations, understanding the factors that control these variations is of particular importance to management. The search for environmental controls of recruitment has been an important component of fisheries research at least since the work of HellandHansen \& Nansen (1909) and Hjort (1914), and has led to many hypotheses still discussed in the fish ecology literature, i.e. match-mismatch (Cushing 1969, 1990), stability window (Lasker 1978), member vagrant (Sinclair 1988), optimal environmental window (Cury \& Roy 1989), fundamental triad (Bakun 1996) and others.

In most marine systems and for many fish populations, relationships between environment and recruitment have been proposed, but they have often been contested or have failed when retested with new and longer sets of observations (see Myers 1998). Two gen- 
eralisations emerge: (1) environmental control on recruitment is more obvious and robust at the edge of the biogeographical limits of a species (Myers 1998); and (2) when relationships have failed, it has often been argued that some new controls on recruitment were at play but were not considered.

Although this issue has been a major area of research for a century, and despite the number of available theories and hypotheses proposed to relate interannual fluctuations in fish recruitment to variations in environmental conditions, it appears that environmental controls on recruitment are likely to exist but the factors at play are difficult to identify, numerous and their respective importance may change with time. In most cases only a small subset of environmental controls (or proxies for the controls) are accessible to measurement or are actually measured, and these factors interact in ways that are complex and not always well understood. The multiplicity and complexity of the environmental controls limit our ability to adequately understand and model environmentrecruitment relationships.

The issue of multiple interacting factors controlling biological processes is not new in ecology. During the first part of the 19th century, agricultural work on the nutrition of terrestrial plants already recognised the interaction between several minerals and led to the definition of the Sprengel-Liebig Law of the Minimum (van der Ploeg et al. 1999), which states that yield is proportional to the amount of the most limiting nutrient. By analogy-and despite the fact that the processes involved are different-survival of early stages of fish (eggs and larvae) is influenced by multiple factors, and it can be assumed that recruitment is ultimately controlled by the most limiting factor, i.e. the one than generates the greatest mortality (or the lowest survival), a view that is close to that of the critical period hypothesis proposed by Hjort (1914).

Recently, an increasing body of literature has been devoted to regression models known as quantile regression models (see Cade et al. 1999). Such models can be easily applied to the specific case of limiting factors in an ecological context and therefore appear as good candidates for modelling environmentrecruitment relationships.

In the present study, we reanalysed environmentrecruitment relationships that have been described for 4 fish stocks, using quantile regression models. We adapted the statistical test to the specific case of autocorrelated time series a common feature of environment time series in the ocean. We then applied the model to the 4 case studies for which environmentrecruitment relationships have been described and compared the results of quantile regression models to standard linear regression.

\section{METHODS}

Background to the quantile regression model. Most regression models are designed to provide estimates of the mean value of the distribution (of the biological response) as a function of known factors (environmental conditions). The residual variance (i.e. not explained by the regression model) is generally considered as white noise (i.e. unstructured) and is often assumed to follow a normal distribution. Least-squares regression, which provides an estimation of the mean, explicitly includes what are thought to be the controlling factors but also implicitly incorporates unmeasured variables which are contained in the error term. In the case of environment-recruitment relationships, numerous environmental factors may control recruitment but one can never be sure that all these factors are measured and included in the statistical models developed. In addition, the nature of environmental factors which can limit recruitment may fluctuate from year to year.

Standard least-squares regression is commonly used to model the conditional mean of a response variable (e.g. recruitment), but alternative regression techniques exist which can be used to model various parts of the distribution (Mosteller \& Tuckey 1977). The regression technique that is used here is known as quantile regression and was developed by Koenker \& Basset (1978). It consists of adjusting regressions on various parts of the distribution which correspond to various quantiles. The regression method is distribution independent and regression parameters are obtained by minimising a function of the absolute deviation between observations $y$ and regression estimates $\hat{y}$ weighted by the quantile $\tau$. The function of absolute deviations to be minimised is expressed as follows:

$$
I_{\tau}=\left[\sum \tau\left(y-\hat{y}_{\tau}\right)_{y>\hat{y}_{\tau}}+\sum(1-\tau)\left(\hat{y}_{\tau}-y\right)_{y<\hat{y}_{\tau}}\right]
$$

where $y^{\prime}$ s are individual observations and $\hat{y}_{\tau}{ }^{\prime}$ s are the corresponding estimations from the regression model for quantile $\tau$. By modelling the upper quantiles $(\tau>$ 0.8 ) it is possible to describe the recruitment potential (i.e. maximum) rather than the mean. Although the upper regression quantiles do not describe the exact upper limit of the distribution function, they can provide an approximation which is consistent with the ecological concept of limiting factor.

The results of quantile regression for the full range of quantiles $[0,1]$ allows for the identification of potential interactions between measured and unmeasured factors (Cade \& Noon 2003). Two different response distributions can be observed: (1) the homogeneous response, in which measured and unmeasured factors are simply additive and therefore not interacting (in 
this case, the slopes of the regressions for different quantiles are parallel to each other); (2) the heterogeneous response, in which interaction between measured and unmeasured factors is effective (Cade et al. 2005), as is the case in the Sprengel-Liebig Law of the Minimum (the slopes of the regressions vary between quantiles and are generally steeper for higher quantiles). A controlling factor can be identified as limiting when the slope tends to be steeper for upper quantiles and when it is significantly different from zero for high quantiles.

We used linear quantile regressions for quantiles ranging from 0.10 to 0.90 . All quantile fits were performed using quantreg, a library available for quantile regression in R (Ihaka \& Gentleman 1996, R Development Core Team 2004, Koenker 2005).

Testing the significance of quantile regression for autocorrelated time series. Comparison of time series using correlation analysis is often biased by autocorrelation in the data. Serial autocorrelation arises when there is a degree of persistence in the data series so that observations that are close in time are more similar than observations that are further apart. This results in the assumption of independence between data being violated, which in turn artificially inflates the apparent number of degrees of freedom. Correlation tests performed without accounting for positive autocorrelation (either temporal or spatial) are less conservative than they should be and tend to be biased towards higher rates of rejection of the null hypothesis (i.e. declare the correlation to be significant) (Legendre \& Legendre 1998). A number of solutions have been proposed to correct for the effects of autocorrelation. These often consist of 2 main types of strategies: (1) adjustment of the degrees of freedom in the statistical tests to compensate for the autocorrelation, or (2) removal of the autocorrelation by prewhitening of the data series prior to statistical testing (Thompson \& Page 1989, Pyper \& Peterman 1998).

Although these solutions can be well suited for correlation analysis, they are not always transferable when testing the significance of regression coefficients for which the theoretical distribution under the null hypothesis are unknown. This is also true within a quantile regression context. The approach chosen here is a procedure which is used to construct the empirical distributions of regression coefficients under the null hypothesis $\left(H_{0}\right)$. The statistical significance of the regression can then be calculated by comparing the observed regression coefficient to the empirical distribution under $H_{0}$.

A central issue is the definition of $H_{0}$ and $H_{1}$ (the alternative hypothesis) and the ability to construct the empirical distribution of the regression coefficient under $H_{0}$. The hypotheses are defined here as follows:
$\left(H_{0}\right)$ the observed relationship between recruitment and the environment is not different from the relationship between recruitment and a randomly generated environmental time series which would have similar properties (identical number of observations, identical statistical distribution and identical temporal structure) as the observed one; $\left(H_{1}\right)$ the observed relationship between recruitment and environment is different from the relationship between recruitment and a randomly generated environmental time series which would have similar properties as the observed one. Any such series is called a surrogate time series. The statistical test is performed by calculating the empirical distribution of the regression coefficient between recruitment and environment under $H_{0}$ and then testing whether the observed regression belongs to this empirical distribution ( $H_{0}$ not rejected) or not $\left(H_{0}\right.$ rejected) at a given probability level. The empirical distribution of the regression coefficient under $H_{0}$ is obtained by regressing the recruitment time series against a large number of surrogates of the environmental time series (here 10000 ).

The surrogate model corresponds to the generation of 'reddened noise' in which linear properties of the time series are fully described by its autocorrelation function or equivalently by its power spectrum. Surrogate data are constructed by adding random phases in $[0,2 \pi]$ to the components of the Fourier transform of the observed time series, and then computing its inverse Fourier transform. This procedure is known as phase randomization (Theiler et al. 1992, Schreiber \& Schmitz 2000). The resulting surrogates are Gaussian and have the same mean, variance and power spectrum as the original data. An example of surrogate time series for the sea surface temperature measured at San Diego is presented in Fig. 1. An application of surrogate time-series analysis in marine ecology can be found in Royer \& Fromentin (2006).

\section{RESULTS}

\section{Analysis of individual stocks}

For each stock, we analysed the relationship between an environmental index (temperature, upwelling or river runoff) and recruitment. First, we computed a simple linear regression and tested for the significance of the relationship without accounting for serial autocorrelation. Second, we tested the significance of the relationship with accounting for autocorrelation in the environmental data series by surrogate testing. Third, we performed linear quantile regression from $\tau=0.10$ to 0.90 and tested the significance of each quantile model while accounting for serial autocorrelation. 

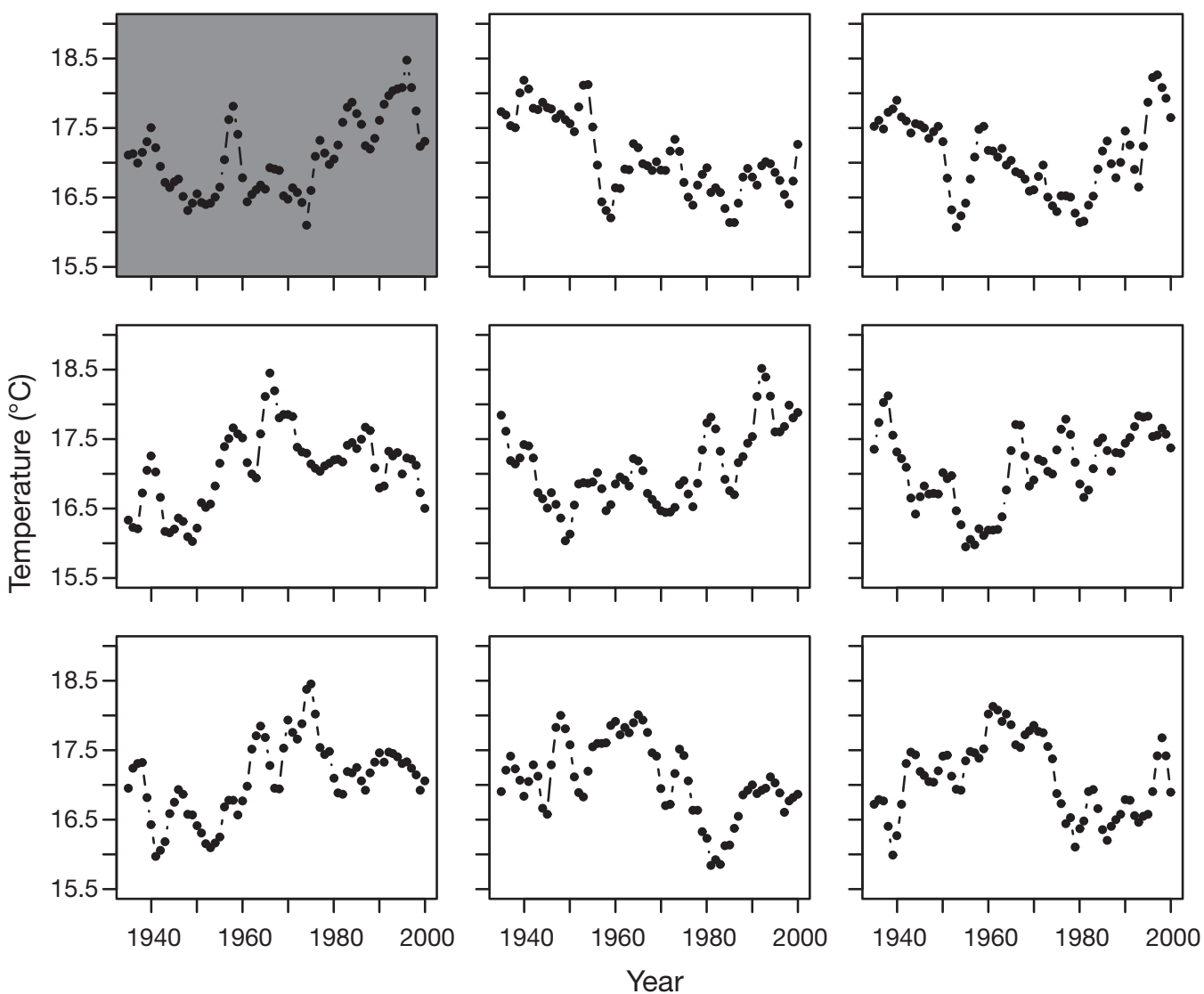

Fig. 1. Fourier transform surrogate time series of sea temperature data from Scripps Pier at San Diego (California). Grey panel shows the original time series. The remaining 8 panels show examples of surrogates in which the mean, variance and autocorrelation function of the original time series have been preserved

\section{Northeast Arctic cod}

From 1945 to present, the spawning biomass of Northeast Arctic cod Gadus morhua has fluctuated between 100000 and $1200000 \mathrm{t}$, mostly as a result of variations in recruitment levels. The influence of temperature on the recruitment of Northeast Arctic cod has been largely described. Recent work by Ottersen et al. (2006, p. 230) summarises the current state of knowledge as follows: 'sea temperature became established as an important influence on recruitment, at least in the sense that cold years never provide a strong year class $[\ldots]$. The explanatory mechanisms involve inflow of warmer, prey-rich Atlantic water masses from the south-west $[\ldots]$. During the later decades a clear, positive temperature-recruitment correlation has evolved, a link that earlier was weak or non-existent $[\ldots]^{\prime}$. This description typically falls in a 'limiting factor' type model, with low temperature limiting year-class strength of cod, and is therefore an appropriate case study for application of the quantile regression model.
Year-class strength of Northeast Arctic cod for the years 1943 to 2002 was estimated by the number of recruits to the stock at age 3 for the years 1946 to 2005 (ICES 2006, Table 3.27). Temperature data were taken from Ottersen et al. (2006) and correspond to temperature measurements at the Kola section in the Barents Sea from December through to March (Fig. 2) as in Tereshchenko (1996). We consider temperature in the year of birth of each annual cohort of cod.

The standard linear regression of recruitment against temperature indicate a positive relationship (slope $=252 \times 10^{6}$ ind . degree $\left.{ }^{-1}\right)$. When no correction is applied for autocorrelation, the relationship appears significant $(p=0.017)$. When autocorrelation is accounted for by surrogate testing, the regression slope remains significant $(p=0.032)$.

The slope of quantile regressions are positive and similar throughout the range of quantile explored (min: $123 \times 10^{6}$ ind. degree ${ }^{-1}$; max: $318 \times 10^{6}$ ind. degree ${ }^{-1}$; Fig. 2d). This suggests that unexplained variability in recruitment may be due additional factors but that these factors are not in interaction with temperature 

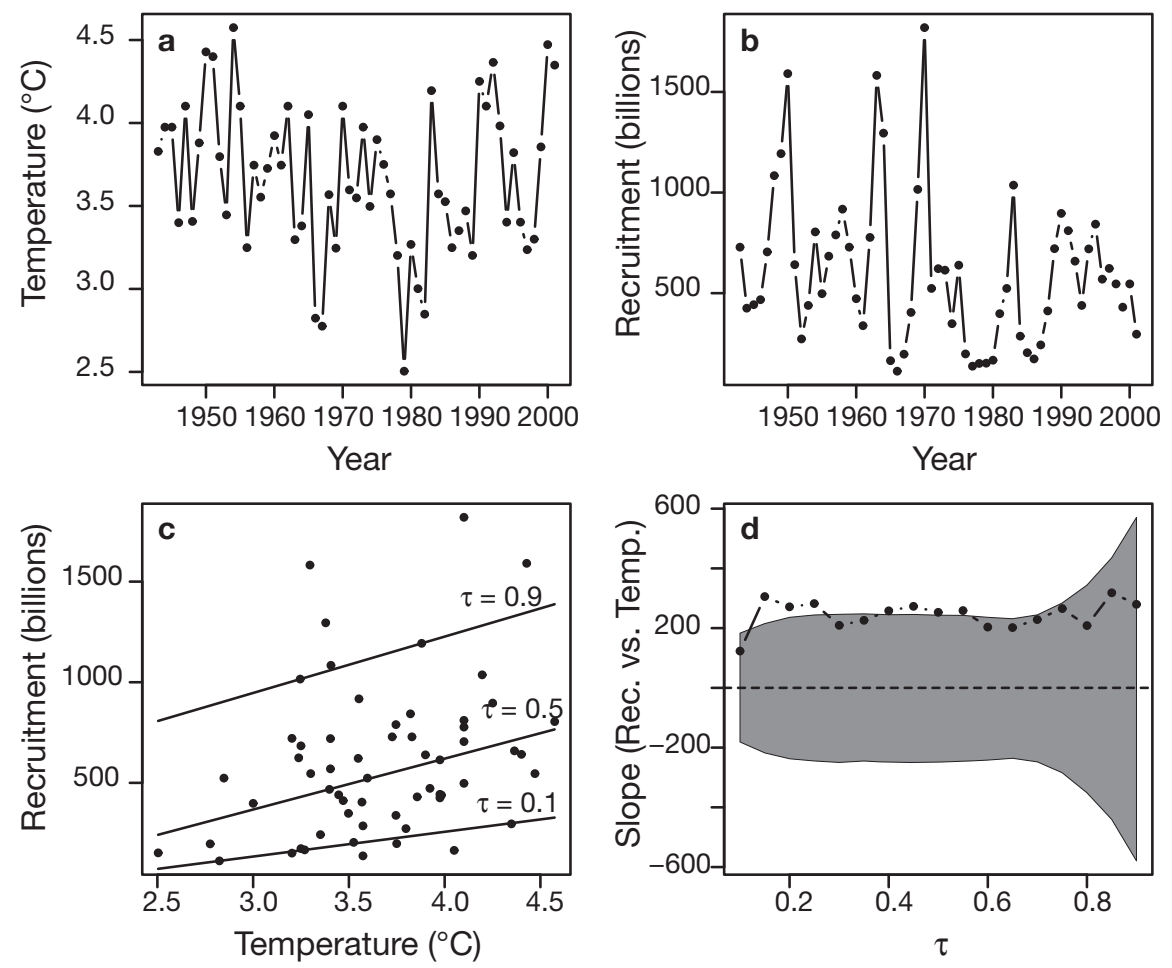

Fig. 2. Gadus morhua. Relationship between recruitment of Northeast Arctic cod and temperature. (a) Time series of sea temperature at the Kola section averaged over December-March. (b) Time series of recruitment at age 3. (c) Recruitment vs. temperature; lines indicate: regressions for quantiles $(\tau)$ 0.10, 0.50 and 0.90 . (d) Slope of quantile regression as a function of $\tau$ [0.10-0.90]; shaded area indicates the envelope of $95 \%$ of the slopes under $H_{0}$ (i.e. no relationship between recruitment and temperature)

(homogeneous rather than heterogeneous model, sensu Cade \& Noon 2003). However, it is noticeable that high recruitment has never been observed at low temperature levels (Fig. 2c), a feature that has been described by Ottersen et al. (2006) but which is not well captured by the upper quantile regression slopes. The application of the regression models indicates that the relationship between cod recruitment and temperature is rather weak, whether it is analysed using conventional least-squares regression ( $p=0.032$ ) or quantile regression (not significant for upper quantiles), and that most of the variability in recruitment is explained by factors other than temperature recorded at the Kola section.

\section{Atlanto-Scandian herring}

During the past century, the spawning biomass of Atlanto-Scandian herring Clupea harengus has fluctuated between nearly 0 and 16 million t. Long-term fluctuations in herring biomass have resulted from variations in recruitment levels, and it has been hypothesised that survival of herring larvae is highly dependent upon the inflow of Atlantic water masses into the northeast Atlantic region (Toresen \& Østvedt 2000). This inflow is reflected in the temperature measurements realised at the Kola meridian (Barents Sea) during the winter months. The close relationship between interannual variations in temperature measured at the Kola section and year-class strength of Atlanto-Scandian herring has been reported by Toresen \& Østvedt (2000) and reanalysed by Megrey et al. (2005). As for Northeast Arctic cod, the recruitment of Atlanto-Scandian herring seems to be limited by low temperatures and therefore constitute a good case study for quantile regression analysis.

The analysis was performed using biological and environmental data as in Megrey et al. (2005). Time series of recruitment at age 3 from 1908 to 1998 were taken from Toresen \& Østvedt (2000) and the temperature recorded at the Kola section were averaged over the months January to April, from 1905 to 1995 (Tereshchenko 1996) (Fig. 3).

Our analysis confirms the positive relationship between Kola temperature and recruitment (slope = $90 \times 10^{9}$ ind. degree ${ }^{-1}$ ). When no correction for autocorrelation is applied, the relationship is highly significant $\left(p=1.44 \times 10^{-5}\right)$. This remains true when autocorrelation is accounted for $\left(\mathrm{p}=4 \times 10^{-4}\right)$. 

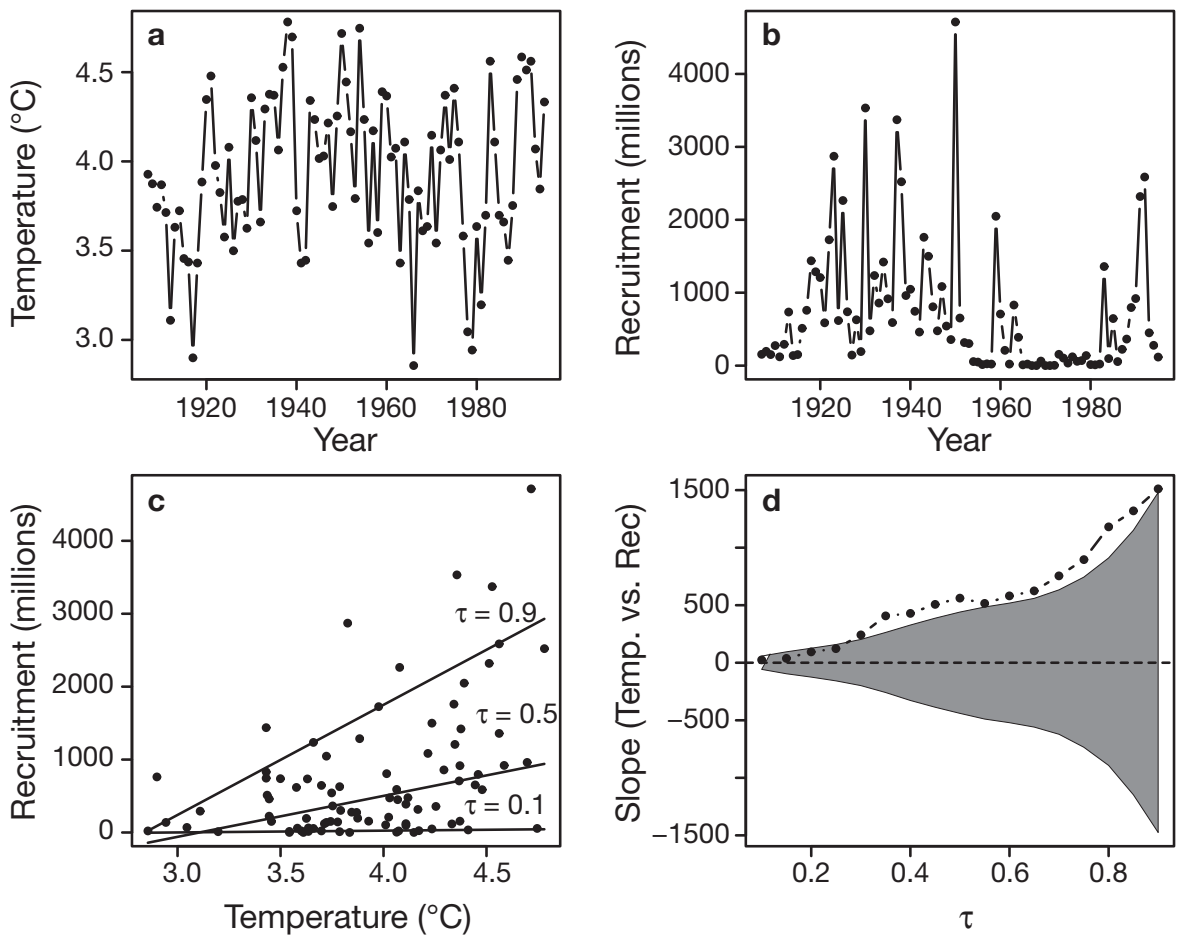

Fig. 3. Clupea harengus. Relationship between recruitment of Atlanto-Scandian herring and temperature. (a) Time series of sea temperature at the Kola section averaged over January-April. (b) Time series of recruitment at age 3. (c) Recruitment vs. temperature; lines indicate regressions for quantiles 0.10, 0.50 and 0.90. (d) Slope of quantile regression as a function of quantile [0.10-0.90]. Shaded area as defined in Fig. 2

Contrary to the Northeast Arctic cod example, there are great variations in the slope of the quantile regression as quantiles increase (Fig. 3c). Slope values for lower quantiles are close to zero and increase steadily towards their highest values for the upper quantiles $\left(150 \times 10^{9}\right.$ ind. degree ${ }^{-1}$ for $\left.\tau=0.90\right)$. Despite an increase in the dispersion of slope values under the null hypothesis as $\tau$ increases, the relationship between temperature and herring recruitment is always positive and remains significant $(\mathrm{p}<0.05)$ for all $\tau>$ 0.30 . These results suggest that temperature is acting as a limiting factor and that the underlying model is a heterogeneous model (i.e. other factors interact with temperature).

\section{Bay of Biscay anchovy}

The population of anchovy Engraulis encrasicolus in the Bay of Biscay is known to fluctuate greatly as a result of interannual variations in year-class strength, leading to harvest fluctuating historically between 80000 and $<3000 \mathrm{t}$. Individual fish recruit at age 1 and it is believed that interannual variations in recruitment levels are driven by environmental factors. Predicting recruitment of the Bay of Biscay anchovy has been a major concern since the fisheries mainly catch 1 yr old individuals (which dominate the population in number and biomass) before they can be assessed by scientific surveys. Upwelling intensity in spring and windinduced stratification breakdown have been identified as the major predictors for year-class strength (Borja et al. 1998, Allain et al. 2001). Other possible factors related to the Gironde river plume extent, downwelling and stratification have been explored, but previously published results did not identify these factors as significant controls of recruitment variability.

In the present study, we used quantile regressions to reanalyse the relationship between anchovy recruitment and upwelling intensity and retest the relationship between recruitment and the runoff from the Gironde estuary, since interannual variations in the dynamics of hydrological structures over the Bay of Biscay in spring are greatly influenced by the river runoff during the preceding months (Planque et al. 2004).

The population abundance and biomass has been regularly assessed since 1986 and anchovy recruitment data for the period 1987 to 2005 are taken from the assessment working group report (ICES 2005). We used the upwelling index which is currently provided to the assessment working group as an indication of environmental conditions for recruitment. The index was developed by Allain et al. (2001) and is calculated 

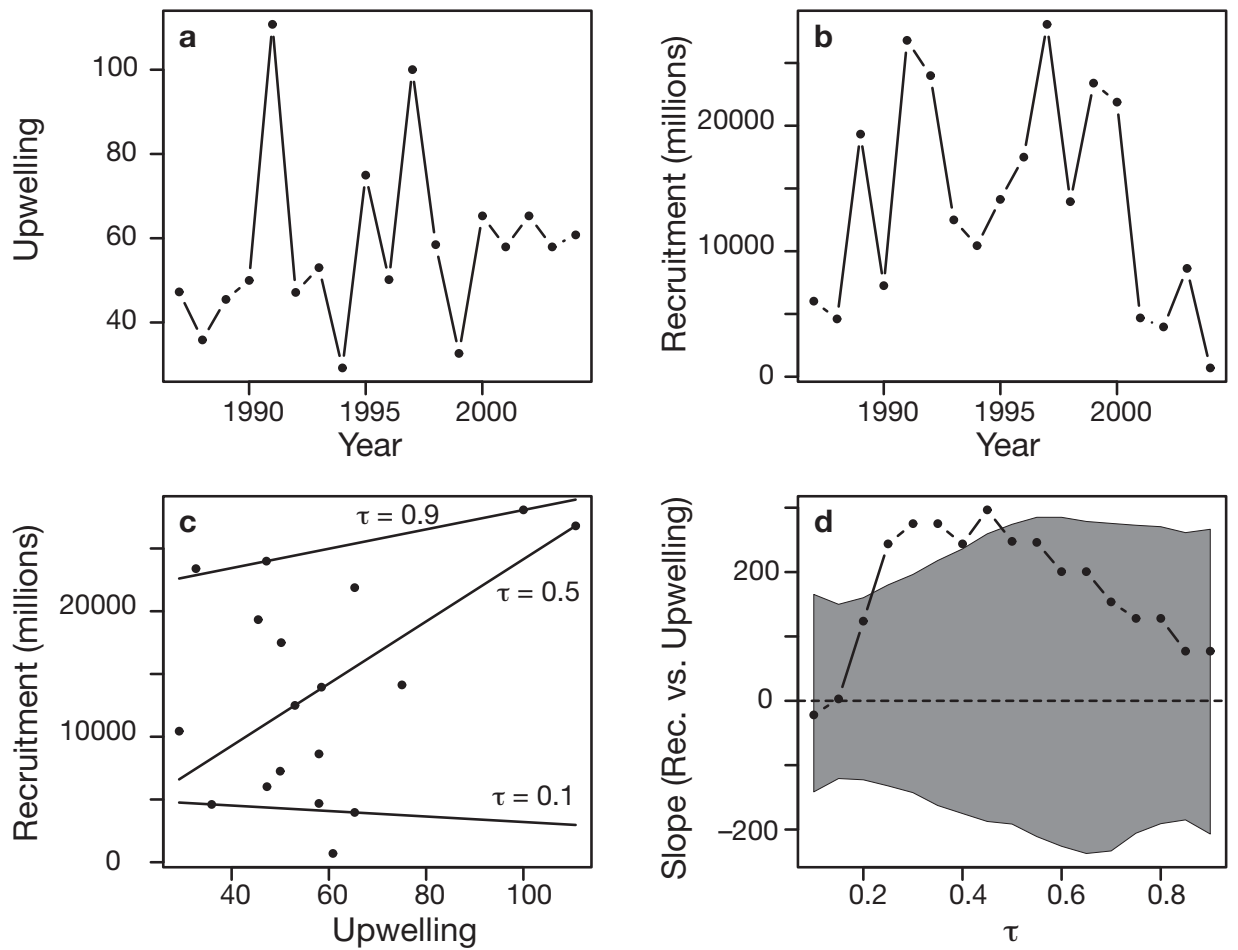

Fig. 4. Engraulis encrasicolus. Relationship between recruitment of Bay of Biscay anchovy and upwelling. (a) Time series of upwelling index, March-July. (b) Time series of recruitment at age 1. (c) Recruitment vs. upwelling index; lines indicate regressions for quantiles 0.10, 0.50 and 0.90. (d) Slope of quantile regression as a function of quantile [0.10-0.90]. Shaded area as defined in Fig. 2
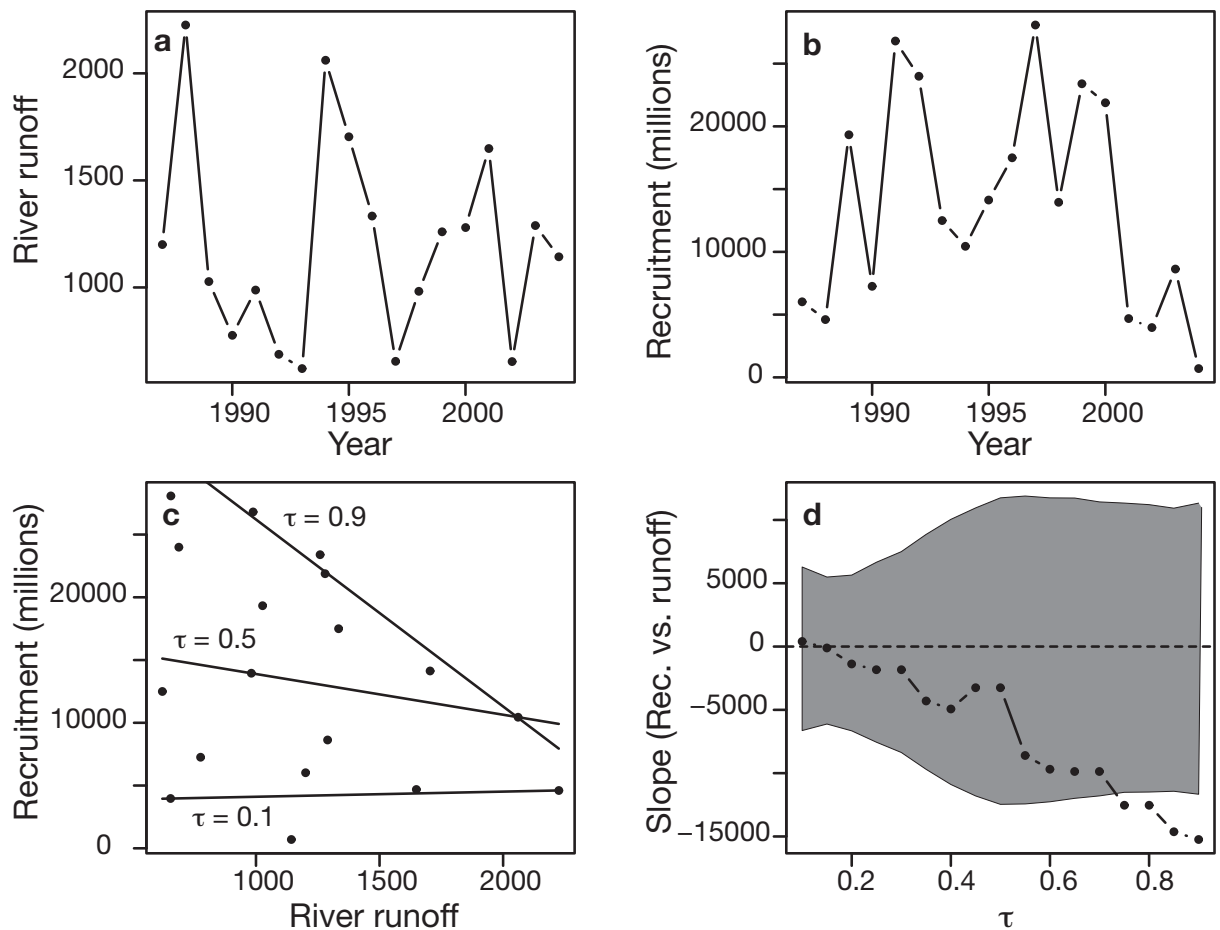

Fig. 5. Engraulis encrasicolus. Relationship between recruitment of Bay of Biscay anchovy and river runoff. (a) Time series of river runoff index, February-April. (b) Time series of recruitment at age 1. (c) Recruitment vs. river runoff; lines indicate regressions for quantiles 0.10, 0.50 and 0.90. (d) Slope of quantile regression as a function of quantile [0.10-0.90]. Shaded area as defined in Fig. 2 
as the sum of the weekly positive vertical transport velocity (in $\mathrm{m} \mathrm{s}^{-1}$ ) along the coast of Les Landes (from the coast to a depth of $50 \mathrm{~m}$ ), simulated by a 3D hydrodynamic model (Lazure \& Jégou 1998). Weekly means were summed from March to July to obtain an annual index (Fig. 4a). The Gironde river index (Fig. 5a) is calculated as total runoff (in $\mathrm{m}^{3} \mathrm{~s}^{-1}$ ) over the months February to April, as this period precedes the spawning season (Motos et al. 1996, Planque et al. 2006).

As expected on the basis of previously published results, there is a positive relationship between upwelling intensity and anchovy recruitment (slope = $165 \times 10^{6}$ ind. unit ${ }^{-1}$ ). However, when uptated from previously published results, the regression is no longer significant $(p=0.097)$. When autocorrelation is accounted for the relationship is significant at $\mathrm{p}=$ $0.036^{\mathbf{1}}$.

In the quantile regression models, the slope varies with $\tau$ but is significant neither at low nor high $\tau$ (Fig. 4d) so that upwelling cannot be seen as a limiting factor to recruitment but simply as a weakly correlated factor. The relationship seems to be driven only by years 1991 and 1997 which showed simultaneously high upwelling and high recruitment.

The linear regression between Gironde runoff and recruitment is negative (slope $=-5.840 \times 10^{6}$ ind. unit $^{-1}$ ) but is not significant ( $\mathrm{p}=0.195$ if autocorrelation is not accounted for and $p=0.144$ if it is).

In the quantile regression models, the slope is almost always negative and decreases with increasing quantiles (Fig. 5d). For high quantiles the slope is steepest and significant $(p<0.05)$. These variations in slope value as a function of $\tau$ suggest that river runoff is a limiting factor of Bay of Biscay anchovy recruitment with high runoff never associated with high recruitment. This factor is interacting with additional unmeasured factor(s) (heterogeneous model).

\section{Pacific sardine}

The Pacific sardine Sardinops sagax fishery of the west coast of North America reached historical landings of up to $720000 \mathrm{t}$ with a biomass estimated at 3.5 million $t$ in 1932. The decline which followed brought the stock biomass down to less than $10000 \mathrm{t}$ and the stock began to recover in the early 1980s (Jacobson \& MacCall 1995). It is currently estimated to

\footnotetext{
1 It may seem counter-intuitive that $\mathrm{p}$ could decrease when autocorrelation is accounted for. However, this result is expected when the environmental time series is negatively rather than positively autocorrelated. This appears to be the case of the upwelling time series considered here
}

be around 1 million $\mathrm{t}$ (Pacific Fishery Management Council 2006).

The relationship between temperature and Pacific sardine has long been established and studied. Temperature is thought to affect egg and larval stage duration (Butler et al. 1993) or zooplankton availability for larvae (Murphy 1960). Low temperature may also be a proxy for increased upwelling intensity, resulting in advection of sardine larvae offshore where survival is poor (Murphy 1960). In addition, low temperature has been thought to shorten and delay sardine spawning season (Marr 1960). Stock-recruitment models which include temperature have been proposed and the relationship seems more evident when production (expressed as recruitment over spawning stock biomass) is considered, rather than recruitment alone (Jacobson \& MacCall 1995).

The stock of Pacific sardine is one of the very rare examples in which an environmental parameter (temperature) is actually used in the assessment procedure (Pacific Fishery Management Council 2005) to set the recommended catch levels.

We did not consider recruitment, but recruitment success as proposed in Jacobson \& MacCall (1995). Recruitment success of Pacific sardine was taken as the number of age 2 recruits (in millions) over spawning biomass (in $1000 \mathrm{t}$ ) in their year of birth. Temperature data are averages of temperature recorded at Scripps Pier (La Jolla, California) during the 3 seasons preceding recruitment (at age 2), i.e. the period extending from $1 \mathrm{yr}$ before birth to $1 \mathrm{yr}$ after birth of the year class studied. The data are taken from Jacobson \& MacCall (1995) for the period 1935 to 1961 and from the SAFE reports (Pacific Fishery Management Council 2005) for the period 1983 to 2002. Two important features are noticeable for the eastern Pacific: (1) the sardine time series was interrupted during the period 1962 to 1982 when the stock collapsed and (2) the temperature regime in recent years is warmer than in the earlier period (Fig. 6a). We used the full temperature time series (1935 to 2000) for the construction of the environmental surrogates, but only the periods prior to 1962 and after 1982 were considered for comparison with sardine recruitment success data.

The relationship between temperature and recruitment success is positive and significant $(p=0.019)$. However, when autocorrelation is accounted for, the regression is no longer significant $(p=0.407)$. This is explained by the very strong autocorrelation in the temperature series (due to the calculation of temperature as a moving average over a $3 \mathrm{yr}$ time period) associated with a long-term increase in temperature between the 2 periods considered. When these 2 effects are accounted for (by surrogate testing), the 

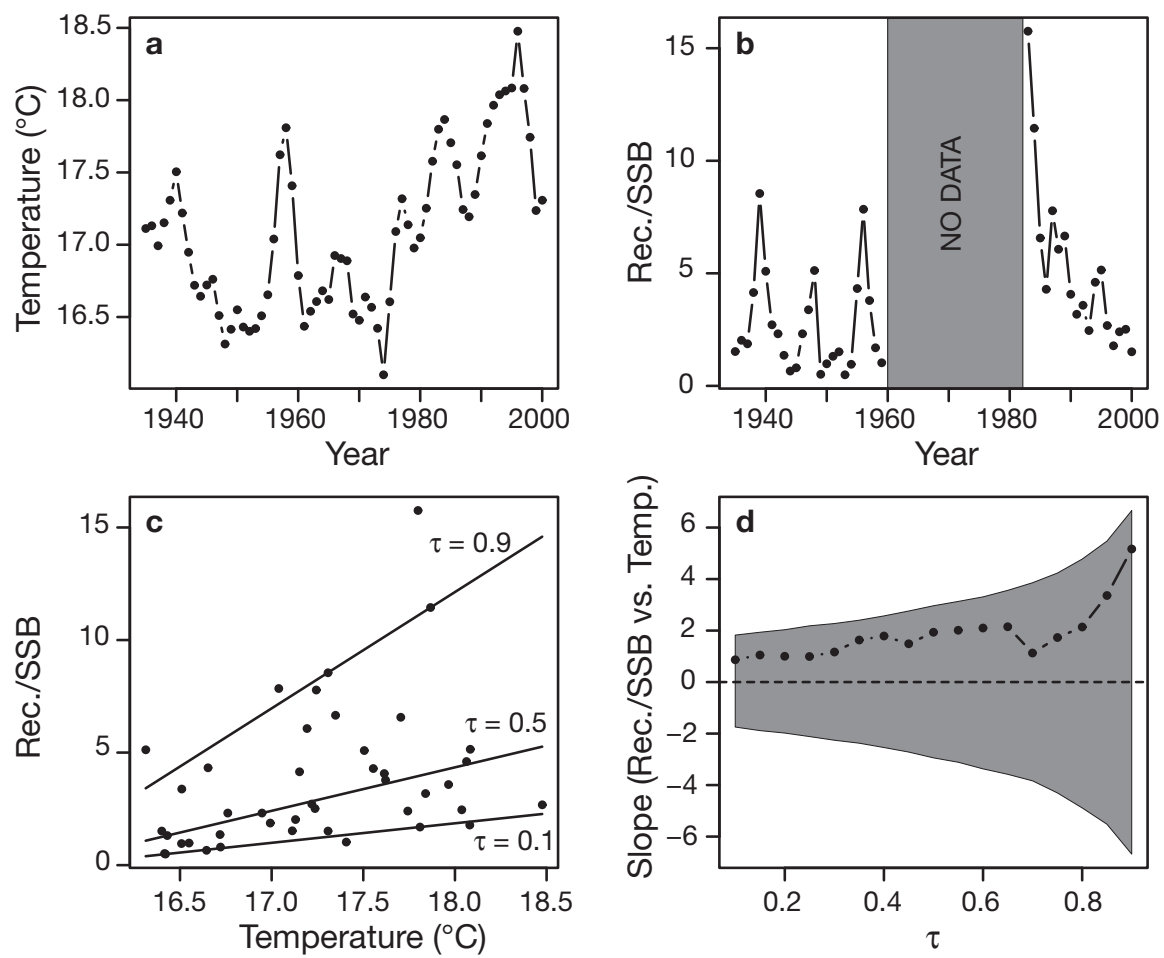

Fig. 6. Sardinops sagax. Relationship between recruitment success of Pacific sardine and temperature. (a) Time series of sea temperature at Scripps Pier averaged for the 3 seasons preceding recruitment. (b) Time series of recruitment success at age 2. (c) Recruitment success vs. temperature; lines indicate regressions for quantiles 0.10, 0.50 and 0.90. (d) Slope of quantile regression as a function of quantile [0.10-0.90]. Shaded area as defined in Fig. 2. SSB: spawning stock biomass

power of the test dramatically falls resulting in the correlation being no longer significant.

The slopes of quantile regressions vary with greater slopes for high values of $\tau$. This suggests that temperature is a limiting factor for sardine recruitment in the Pacific with high recruitment not being observed when temperatures are low. However, the slopes are not significant at low or high $\tau$ so that the validity of this conclusion cannot be demonstrated and may simply be an artifact of strong autocorrelation in the temperature and recruitment time series.

\section{DISCUSSION AND CONCLUSIONS}

The influence of environment on recruitment is an intrinsically complex problem in which controlling factors are difficult to identify, may be numerous, and their relative contribution may vary with time. The use of quantile regression models therefore appears attractive since these models can specifically handle cases where not all controlling factors are measured or even known. The reanalysis of the relationships between recruitment and the environment for 4 welldocumented fish stocks provides an opportunity to assess the benefits and the limitations in applying quantile regression to environment-recruitment studies. In the present cases, we specifically concentrated on the use of quantile regression as a tool to detect factors which could limit fish recruitment.

Northeast Arctic cod and Atlanto-Scandian herring provide 2 interesting examples to compare. Both stocks are located in boreal waters and their recruitment appears to be related to similar, or at least connected, processes, since their respective recruitment is linked to sea temperature measures at the Kola meridian section. The 2 species compete for a common food resource (capelin Mallotus villosus), but at distinct stages in the life-cycle. Herring feed on larval capelin whilst cod feed on adult individuals (Hamre 2003). Adult cod also feed directly on adult herring (Johansen 2002). In such context the effect of temperature on the recruitment of both species should be complicated by trophic interactions which are not explicitly taken into account in the temperature-recruitment models. Temperature is therefore expected to act as a limiting factor and the relationship should be stronger for high than for low quantiles. For cod, the results from the quantile regressions suggest a homogenenous model (i.e. no interactions with other factors) and the relationship at high quantiles is not significant. This result is counter-intuitive and in opposition to already pub- 
lished material (e.g. Ottersen et al. 2006). From Fig. 2c, it seems that recruitment may be limited to low numbers when temperature is low; however, because of the high scattering of the data, the relationship is not detected as being significant by the quantile regression model. For herring, the results are consistent with expectations under the hypothesis that temperature acts as a limiting factor, with steeper and significant slopes of the regressions for high quantiles.

The case of Bay of Biscay anchovy falls in the category of relationships which fail after retesting when additional years of data become available. The relationship between anchovy recruitment and upwelling intensity in spring was established by several authors based on data up to 1997 (Borja et al. 1998, Allain et al. 2001), but when recent data are included in the analysis (1998 to 2004) the relationship no longer holds. On the other hand, the extensive exploratory analysis undertaken by Allain et al. (2001) did not retain river runoff as an explanatory variable for fluctuation in the recruitment of Bay of Biscay anchovy. A reanalysis of the runoff-recruitment relationship confirms this result, only if the modelling approach is restricted to conventional regression (i.e. modelling of the mean). When quantile regression models are applied, it appears that the relationship is significant for the upper quantiles $(\tau>0.70)$ which is consistent with runoff acting as a limiting factor to recruitment. The application of the quantile regression model provides new insight into the possible control of anchovy recruitment in the Bay of Biscay and indicates that strong river runoff during the spring period may limit recruitment, a result that was not revealed by previous analyses.

One important consideration (which remains valid outside the context of quantile regression) was the explicit incorporation of temporal autocorrelation in the statistical analyses. Statistical bias induced by autocorrelation is a common problem in environmentrecruitment studies but is often ignored. In 3 of the 4 cases, autocorrelation was not strong enough to alter the outcome of the statistical tests performed with standard least-squares regression. However, in the case of the Pacific sardine, it appears that the strong relationship between temperature and recruitment success cannot be statistically established and the question remains as to whether the relationship previously proposed by Jacobson \& MacCall (1995) truly reflects an underlying causal mechanism or simply results from an artifactual bias in the original statistical tests. The general increase in the slope of the temperature-recruitment relationships from low to high quantiles indicates that temperature may nonetheless act as a limiting factor for recruitment with high recruitment success never observed when temperature is low.
These 4 case studies reveal that the results from quantile regression are not straightforward extensions of conventional regressions. For Northeast Arctic cod and Pacific sardine, the original relationships with temperature were not statistically significant in the quantile model (for $\tau>0.80$ ). For Atlanto-Scandian herring the relationship was confirmed and temperature clearly appeared as a limiting factor to recruitment. Finally, for the Bay of Biscay anchovy the published relationship with upwelling was not confirmed but the previously undetected relationship with river runoff was established. In this specific case, it was only by using a quantile model that the relationship could be detected as statistically significant.

One interesting feature of quantile regression models is their ability to provide forecasts of recruitment potential (i.e. maximum, rather than mean) based on environmental conditions in the case when not all environmental controls are measured. By doing so it would be possible to provide advance warning for situations in which recruitment potential is expected to be low, as for example in the case of cold temperature recorded at the Kola section and recruitment of Atlanto-Scandian herring. Such advance warning may be easily communicated to expert and advisory working groups.

Acknowledgements. The authors are grateful to L. Jacobson at NMFS and S. Worley at UCAR for their help in accessing the sardine and temperature data for the eastern Pacific case study, and to A. Karsakov at PINRO for providing the Kola section temperature records. This work has been supported by the project UNCOVER (understanding the mechanisms of stocks recovery) of the European Union 6th framework programme.

\section{LITERATURE CITED}

Allain G, Petitgas P, Lazure P (2001) The influence of mesoscale ocean processes on anchovy (Engraulis encrasicolus) recruitment in the Bay of Biscay estimated with a threedimensional hydrodynamic model. Fish Oceanogr 10: 151-163

Bakun A (1996) Patterns in the ocean. Ocean processes and marine population dynamics. NOAA, California Sea Grant College System, La Jolla, CA

Borja A, Uriarte A, Egaña J, Motos L, Valencia V (1998) Relationships between anchovy (Engraulis encrasicolus) recruitment and environment in the Bay of Biscay (1967-1996). Fish Oceanogr 7:375-380

Butler JL, Smith PE, Lo NCH (1993) The effect of natural variability of life-history parameters on anchovy and sardine population growth. CalCOFI Rep 34:104-111

Cade BS, Noon BR (2003) A gentle introduction to quantile regression for ecologists. Frontiers Ecol Environ 1: 412-420

Cade BS, Terrell JW, Schroeder RL (1999) Estimating effects of limiting factors with regression quantiles. Ecology 80: $311-323$ 
Cade BS, Noon BR, Flather CH (2005) Quantile regression reveals hidden bias and uncertainty in habitat models. Ecology 86:786-800

Cury P, Roy C (1989) Optimal environmental window and pelagic fish recruitment success in upwelling areas. Can J Fish Aquat Sci 46:670-680

Cushing DH (1969) The regularity of the spawning season of some fishes. J Cons Int Explor Mer 33:81-92

Cushing DH (1990) Plankton production and year-class strength in fish populations: an update of the match/ mismatch hypothesis. Adv Mar Biol 26:249-293

Hamre J (2003) Capelin and herring as key species for the yield of Northeast Arctic cod. Results from multispecies model runs. Sci Mar 67:315-323

Helland-Hansen B, Nansen F (1909) The Norwegian Sea: its physical oceanography based on the Norwegian researches 1900-1904. Rep Norw Fish Mar Invest 2:1-360

Hjort J (1914) Fluctuations in the great fisheries of Northern Europe viewed in the light of biological research. Rapp P-V Reun 20:1-228

ICES (2005) Report of the working group on the assessment of mackerel, horse mackerel, sardine, and anchovy. ICES CM 2005/ACFM 08

ICES (2006) Report of the Arctic fisheries working group. ICES CM 2006/ACFM 25:1-584

Ihaka R, Gentleman R (1996) R: a language for data analysis and graphics. J Comput Graph Statist 5:299-314

Jacobson LD, MacCall AD (1995) Stock-recruitment models for Pacific sardine (Sardinops sagax). Can J Fish Aquat Sci 52:566-577

Johansen GO (2002) Temporal and spatial variation in predation on juvenile herring (Clupea harengus L.) by Northeast Arctic cod (Gadus morhua L.) in the Barents Sea in 1984-1997. ICES J Mar Sci 59:270-290

Koenker R (2005) Quantile regression, Vol 38. Econometric Society Monographs. Cambridge University Press, New York

Koenker R, Basset G Jr (1978) Regression quantiles. Econometrica 46:33-50

Lasker R (1978) The relation between oceanographic conditions and larval anchovy food in the California Current: identification of the factors leading to recruitment failure. Rapp P-V Reun 173:212-230

Lazure P, Jégou AM (1998) 3D modelling of seasonal evolution of Loire and Gironde plumes on Biscay bay continental shelf. Oceanol Acta 21:165-177

Legendre P, Legendre L (1998) Numerical ecology, Vol 20. Development in environmental modelling. Elsevier, Amsterdam

Marr JC (1960) The causes of major variations in the catch of Pacific sardine sardinops caerulea (Girard). In: Rosa H Jr, Murphy GI (eds) Proceedings of the world scientific meeting on the biology of sardines and related species, Vol 3. FAO, Rome, p 667-791

Megrey BA, Lee YW, Macklin SA (2005) Comparative analysis of statistical tools to identify recruitment-environment relationships and forecast recruitment strength. ICES J Mar Sci 62:1256-1269

Mosteller F, Tuckey JW (1977) Data analysis and regression. Addison-Wesley, Reading, MA

Editorial responsibility: Howard Browman, Storebø, Norway
Motos L, Uriarte A, Valencia V (1996) The spawning environment of the Bay of Biscay anchovy (Engraulis encrasicolus L.). Sci Mar 60:117-140

Murphy GI (1960) Oceanography and variations in the Pacific sardine population. CalCOFI Rep 8:55-64

Myers RA (1998) When do environment-recruitment correlations work? Rev Fish Biol Fish 8:285-305

Ottersen G, Hjermann DO, Stenseth NC (2006) Changes in spawning stock structure strengthen the link between climate and recruitment in a heavily fished cod (Gadus morhua) stock. Fish Oceanogr 15:230-243

Pacific Fishery Management Council (2005) Status of the Pacific Coast coastal pelagic species fishery and recommended acceptable biological catches: stock assessment and fishery evaluation 2005. Pacific Fishery Management Council, Portland, OR

Pacific Fishery Management Council (2006) Status of the Pacific Coast coastal pelagic species fishery and recommended acceptable biological catches: stock assessment and fishery evaluation 2006. Pacific Fishery Management Council, Portland, OR

Planque B, Lazure P, Jegou AM (2004) Detecting hydrological landscapes over the Bay of Biscay continental shelf in spring. Clim Res 28:41-52

Planque B, Bellier E, Lazure P (2007) Modelling potential spawning habitat of sardine (Sardina pilchardus) and anchovy (Engraulis encrasicolus) in the Bay of Biscay. Fish Oceanogr 16:16-30

Pyper BJ, Peterman RM (1998) Comparison of methods to account for autocorrelation in correlation analyses of fish data. Can J Fish Aquat Sci 55:2127-2140

R Development Core Team (2004) R: a language and environment for statistical computing. R Foundation for Statistical Computing, Vienna. Available at www.Rproject.org

Royer F, Fromentin JM (2006) Recurrent and density-dependent patterns in long-term fluctuations of Atlantic bluefin tuna trap catches. Mar Ecol Prog Ser 319:237-249

Schreiber T, Schmitz A (2000) Surrogate time series. Physica D 142:346-382

Sinclair M (1988) Marine populations: an essay on population regulation and speciation. Washington Sea Grant Program, University of Washington Press, Seattle, WA

Tereshchenko VV (1996) Seasonal and year-to-year variations of temperature and salinity along the Kola meridian transect. ICES CM 1996/C 11:1-24

Theiler J, Eubank S, Longtin A, Galdrikian B, Farmer JD (1992) Testing for nonlinearity in time-series: the method of surrogate data. Physica D 58:77-94

Thompson KR, Page FH (1989) Detecting synchrony of recruitment using short, autocorrelated time series. Can J Fish Aquat Sci 46:1831-1838

Toresen R, Østvedt LJ (2000) Variation in abundance of Norwegian spring-spawning herring (Clupea harengus, Clupeidae) throughout the 20th century and the influence of climatic fluctuations. Fish Fish 1:231-256

van der Ploeg RR, Bohm W, Kirkham MB (1999) On the origin of the theory of mineral nutrition of plants and the law of the minimum. Soil Sci Soc Am J 63:1055-1062

Submitted: December 19, 2006; Accepted: October 14, 2007 Proofs received from author(s): February 13, 2008 